ISAHP 1996, Vancouver, Canada, July 12-15, 1996

\title{
A Decision Support System for Production Investments
}

\author{
Matti Verkasalo and Ken Friesen \\ Nokia Telecommunications, Finland \\ matti.verkasalo@ntc.nokia:com
}

In the electronics and telecommunications industry, the days where it was possible to judge a production investment based strictly on financial retum have past. Such decisions must be linked to corporate strategy in order to ensure that all areas of the company move towards consistent, planned goals. This is especially important in companies whose operations' are dispersed across many locations and where capital investments are large due to a high rate of automation. A production investment must be justified in the context of business strategy and should be documented in the language and form understood by management. For many who are not so familiar with business management, it is very difficult to make an investment proposal which accounts for all the necessary factors.

A joint project between Nokia Telecommunications and the University of Oulu was made with one topic investigating decision problematics in a production environment. Specifically, this study investigated repetitive decisions and the possibility of developing a special tool for such problems. In order for such a tool to be adopted by many users, it must be "ultra easy" to use and cannot demand large time investments from busy managers. This was the target for the pilot tool developed in this project. The tool is very simple in its program structure in that it is solely dedicated to production investment decisions in one company and only the essential functions are included. Using the tool is like "thinking through" the investment in the context of the strategic goals set by management. The end product of the evaluation process is an automatically generated investment proposal which can be finalized with Word for Windows. In this way the format of the proposal is in the language and form required by management.

In the model used in this study, a management team first specifies the longer term goals of the company and gives importance weights to these goals through some formalized method, for example AHP Tree or Expert Choice could be used. These goals and weights form a common criteria for any production investment decision. The constraints of repetitive use of a common upper hierarchy are reported in [1]. At the specific problem level, a decision making team would then evaluate how strongly the current problem is linked to each strategic goal and how the alternatives perform against each goal on an absolute scale. Based on this information, an overall weight for each altemative would then be generated.

In the spring of ' 96 , a pilot version of this tool was developed and piloted in order to determine the real demand and value of such a tool. The pilot tool was pretested and evaluated by business managers. The pilot tool was distributed on an automatically installable floppy disk and includes an embedded electronic questionnaire to provide feedback. Result of this survey will be available in July 1996.

[1] Verkasalo M. (1994) 'Repetitive Use of AHP-Hierarchy'. Proceedings of the 3rd International Sympoșium on the Analytic Hierarchy Process, George Washington University, Washington D. C., USA. 